\title{
OPTIMAL CHOICE AND DESIGN OF DIFFERENT TOPOLOGIES OF DC- DC CONVERTER USED IN PV SYSTEMS, AT DIFFERENT CLIMATIC CONDITIONS IN EGYPT
}

\author{
M. A. Farahat, H. M. B. Metwally, and A. A. A. Mehrem \\ Electrical Power Engineering Department, Faculty of Engineering, \\ Zagazig University, Zagazig, EGYPT.
}

\begin{abstract}
This paper investigates the effect of changing cell temperature and intensity of solar radiation on the choice and design of different topologies of DC-DC converter commonly used in PV systems. Under fluctuation of climatic conditions, the MPP of PV generator will change. The MPPT must adjust the converter duty cycle to track the new MPP. Thus the converter must be chosen to be able to match the MPP under different atmospheric conditions. In addition, when the duty cycle changes as a result of changed climatic conditions, the boundary of the converter design parameters will change. So, these parameters must be chosen to achieve the best performance at all. All these aspects are studied in this work and important results are obtained.

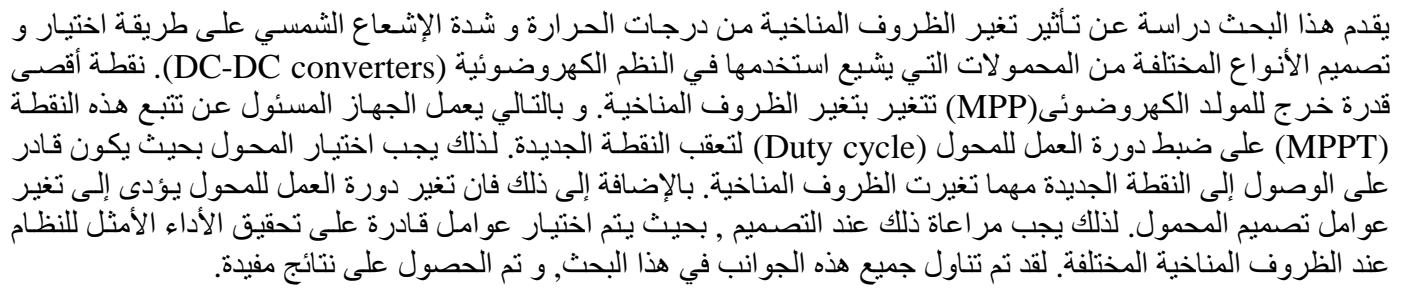

Keywords: MPPT, Maximum power point tracker, DC-DC converter, Optimal design, PV systems.

\section{INTRODUCTION}

When a PV module is directly coupled to a load, the operating point will be at the intersection of its $\mathrm{I}-\mathrm{V}$ curve and the load line. This point may be any where on the I-V curve, and it is seldom to be at the PV module MPP, thus it is not producing the maximum power. As well as, the MPP changes with the module temperature and the solar radiation. This mismatching for the maximum power causes further over-sizing of the PV array and thus increases the overall system cost. To solve this problem, a MPPT can be used to maintain the PV module operating point at the MPP. Most current designs for MPPT consist of three basic components: a switch-mode DC-DC converter, a control circuit, and tracking algorithm [1]. The heart of the MPPT hardware is a switch-mode DC-DC converter. It is widely used in DC power supplies and DC motor drives for the purpose of converting unregulated DC input into a controlled DC output at a desired voltage level [2]. MPPT uses the same converter for regulating the input voltage at the PV MPP to provide load matching for the maximum power transfer [2].

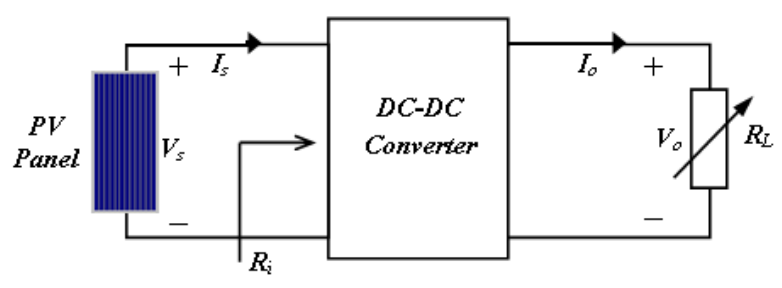

Fig. 1 PV panel connected to a resistive load through DC-DC converter

According to Fig. 2, if a load RLA is connected directly to a PV module, the operating point will be at $\mathrm{A}$. When the load increase to RLC, the operating point will move to $\mathrm{C}$. During this range of load variation, there is only one point at which the PV module provides its MPP. This point is when $\mathrm{RL}=$ Ropt, (point B). But it's very difficult to select a fixed load which matches this value, and even if this is done, this point itself changes under changed climatic conditions. On the other hand, when a DCDC converter is connected between the PV module and the load. The operating point in this case depends on the impedance seen by the module (Ri), which depends on two parameters: RL and D. Thus 
under different loads, the duty cycle can be adjusted to change $\mathrm{Ri}$ to match Ropt at any atmospheric conditions. The function of the other two parts of the MPPT is to achieve this objective. Several methods are proposed for maximum power point tracking algorithm: (1) Curve-fitting (Takashima et al., 2000; Takehara et al., 1997) [3,4], (2) Look-up table (Ibrahim et al., 1999) [5], (3) Open-circuit voltage photovoltaic generator (Masoum et al., 1998; Schoeman et al., 1982) [6,7], (4) Short-circuit photovoltaic generator (Alghuwainem et al., 1994; Noguchi et al., 2002) [8,9], (5) Differentation (David et al., 1968; Bavaro et al., 1988) [10,11], (6) Perturbation and observe ('P\&O') (Kim et al., 1996; Atrash et al., 2005) [12,13], (7) Conductance incremental (“'C.I.'”) (Hussein et al., 1995; Hohm et al., 2003; Liu et al., 2009) [14-16], (8) The only current photovoltaic (Salas et al., 2005) [17,18], (9) Forced oscillations (Tse et al., 2001; Cocconi et al., 1990) [19,20], (10) Artificial intelligence (Wilamowski et al., 2001; Miyatake et al., 2002; Abd El-Shafy et al., 2003; Patcharaprakiti et al., 2005) [21-24]. Where efficiency, advantages, disadvantages and applications of each method are studied in comparative approach . However, the right choice between different topologies for different loads, and the design of these topologies, have not been studied widely, although these issues have a significant effect on the operation of the PV systems. For example, the bad choice of the converter, makes the MPPT less useful, as will be seen later. Also the bad converter design affects significantly on the system efficiency. The aim of this work is to make a comparison between design and analysis of different topologies of DC-DC converters commonly used in PV systems. Also the effect of changing the atmospheric conditions on the converter choice and design will be studied. As a result of this study, the best system configuration can be chosen for a certain load, in order to work properly under different climatic conditions.

\section{MATHEMATICAL MODELING OF PV MODULE}

The PV cell is usually represented by the single or double exponential model [25]. The single exponential circuit model is shown in Fig. 3. This model contains five parameters Isc, Io, Rs, Rp and n (Eq. 1) [2]. The values of these parameters must be determined to reproduce the I-V curve.

The current-voltage relationship of the PV cell is [2]:

$$
\begin{aligned}
& I= \\
& I_{s c}-I_{0}\left[e^{q\left(\frac{V+I R_{s}}{n K T}\right)}-1\right]-\left(\frac{V+I \cdot R_{s}}{R_{D}}\right)
\end{aligned}
$$

The strategy of modeling a PV module is not different from modeling a PV cell. It uses the same PV cell model. The parameters are the same, but only the voltage must be divided by the number of cells. This study uses the single diode model, shown in Fig. 3, which provides fairly accurate results. To make a better model, the effect of temperature on Isc and Io, was included.

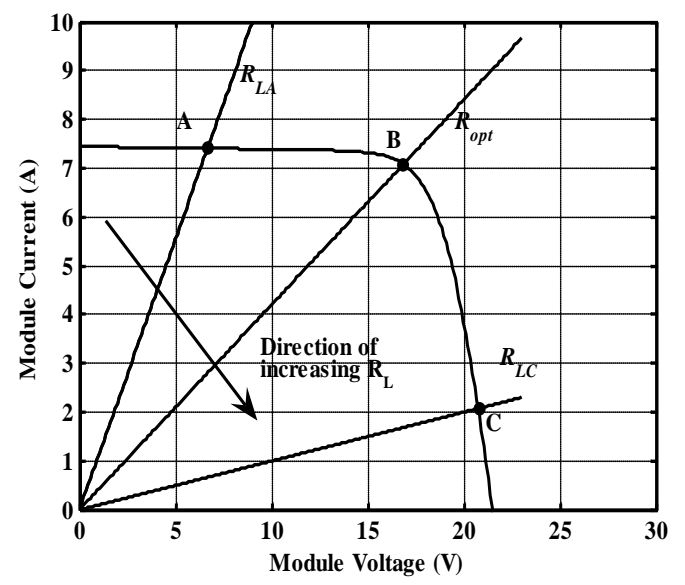

Fig. 2 Location of operating point of a PV module with a variable resistive load

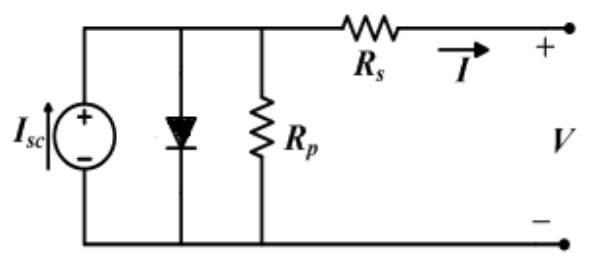

Fig. 3 Equivalent circuit used in the MATLAB simulation

\section{OPERATION AND DESIGN ANALYSIS OF DIFFERENT DC-DC CONVERTERS.}

The DC-DC converter is used in PV systems to detect and track the MPP produced by the PV module, under different atmospheric conditions and connected load. Three basic DC-DC converter topologies are used in PV systems: step down (buck), step up (boost) and step down and up (buck-boost and c'uk) converters [1]. The performance of each topology can be described by the following parameters:

(a) Voltage gain (AV), (b) Current gain (Ai), (c) Input impedance (Ri), (d) Boundary filter inductance (Lb), and (e) Minimum filter capacitance (Cmin). The converter may operate in two distinct modes of operation, the continuous conduction mode (CCM) or the discontinuous conduction mode (DCM). The CCM is preferred for high efficiency and good utilization of semiconductor switches and passive components. The DCM may be used in applications with a special control requirements [1]. The inductance value (Lb) is the minimum inductance value to guarantee that the chopper is working in the CCM. The capacitance Cmin is the minimum capacitance value required to reduce the ripple voltage to a given specified value. The above parameters can be calculated using the relationships in table 1 [1]. These relations were deduced under the assumption that, the converter is lossless and always operates in CCM. 
M. A. Farahat, H. M. B. Metwally, and A. A. A. Mehrem, "Optimal Choice and Design of Different ..."
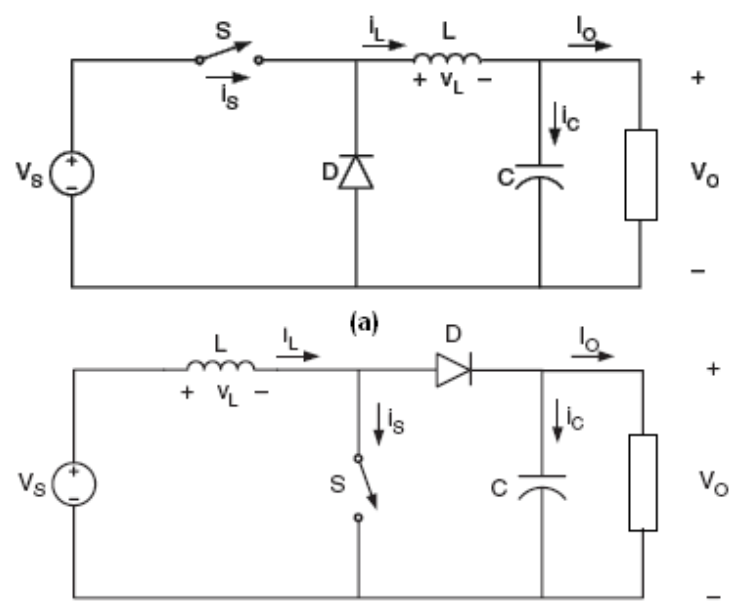

(b)

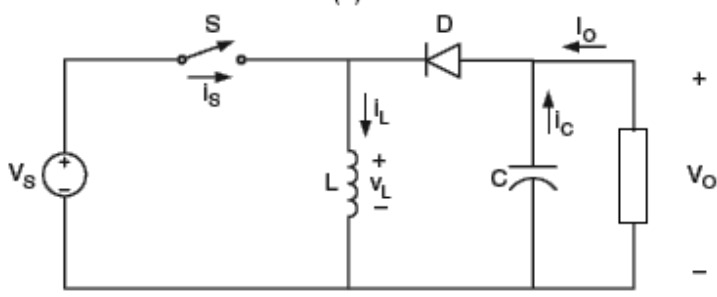

(c)

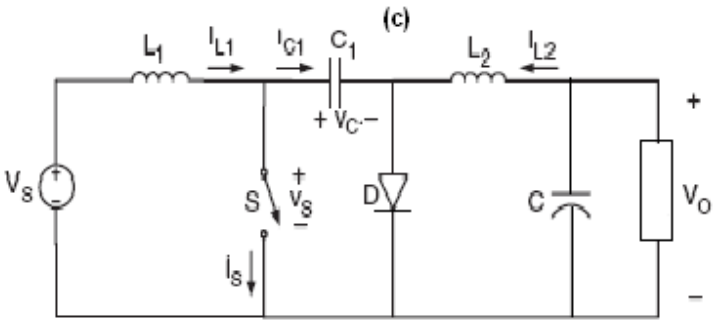

(d)

Fig. 4 DC-DC converter configurations. (a) Buck;

(b) Boost; (c) Buck-Boost; (d) C'uk

3.1 Effect of Duty Cycle on AV and Ai for different Topologies of DC-DC Converter.

Figure 5 shows that, the sensitivity of boost and c'uk converter to the change in $D$ is larger than buck. This property reduces the converter stability.

Table 1, Performance parameters for converters in Fig. 4

\begin{tabular}{|c|c|c|c|c|}
\hline $\begin{array}{l}\text { Paramete } \\
\mathrm{r}\end{array}$ & Buck & Boost & $\begin{array}{l}\text { Buck- } \\
\text { Boost }\end{array}$ & C'uk \\
\hline$\overline{A_{V}}=\frac{V_{D}}{-}$ & $D$ & 1 & $D$ & $D$ \\
\hline$V_{0}$ & & ${ }^{1-D}$ & $\begin{array}{l}1-D \\
1-D\end{array}$ & $\begin{array}{l}1-D \\
1-D\end{array}$ \\
\hline$A_{i}=\frac{D}{I_{s}}$ & $1 / D$ & $1-D$ & $\frac{D}{2}$ & $\bar{D}$ \\
\hline$R_{\mathrm{i}}=\frac{\mathrm{V}_{s}}{u_{s}}$ & $\frac{R_{L}}{D^{2}}$ & $(1-D)^{2} R$ & $\frac{(1-D)^{2}}{D^{2}} R_{L}$ & $=\frac{(1-D)^{2}}{D^{2}} R_{L}$ \\
\hline$L_{b}$ & $\frac{(1-D) R_{L}}{2 f}$ & $\frac{(1-D)^{2} D R_{L}}{2 f}$ & $\frac{(1-D)^{2} R_{L}}{2 f}$ & $\begin{array}{l}L_{1}=\frac{(1-D) R_{L}}{2 D f} \\
=(1-D) R_{L}\end{array}$ \\
\hline \multirow{3}{*}{$C_{\min }$} & & & & $C_{\min }=\frac{2 f}{[1-D] V_{0}}$ \\
\hline & $\frac{L-L V_{0}}{g V_{x} L f^{2}}$ & $\mathbb{V}_{0} D$ & $V_{0} D$ & $8 v_{T} L_{2} f^{2}$ \\
\hline & & $V_{r} R_{L} f$ & $V_{r} R_{L} f$ & $C_{1}=\frac{D V_{o}}{V_{r} R_{L} f}$ \\
\hline
\end{tabular}

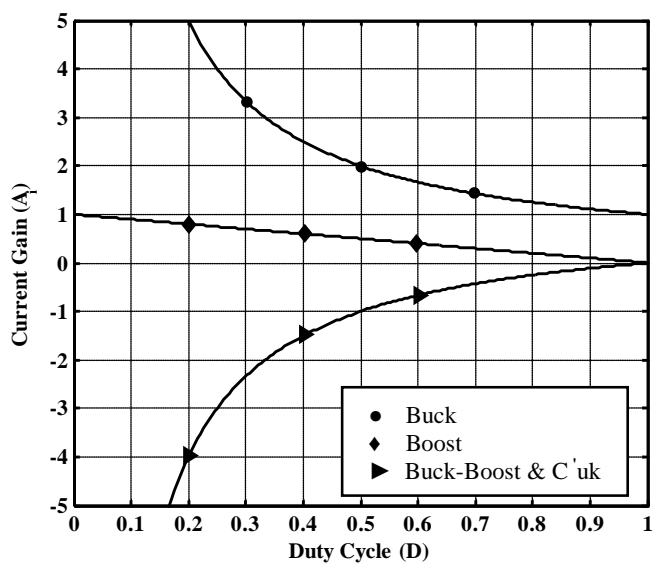

(a)

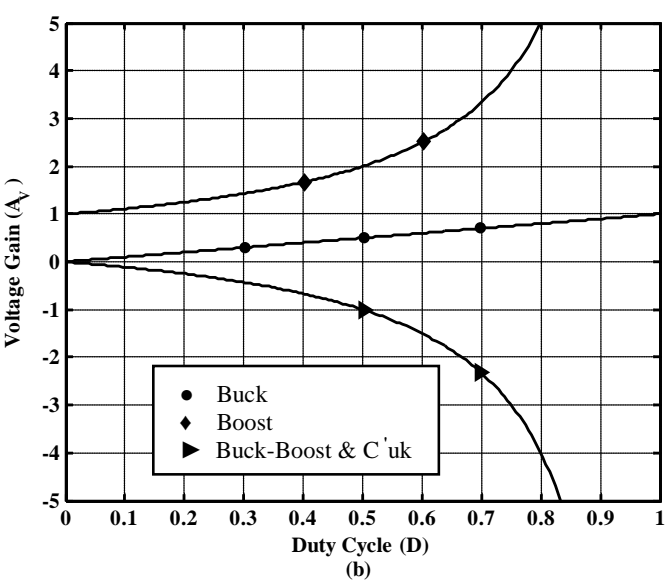

Fig. 5 Effect of D on AV and Ai for different topologies of DC-DC converter (a) Ai (b) AV

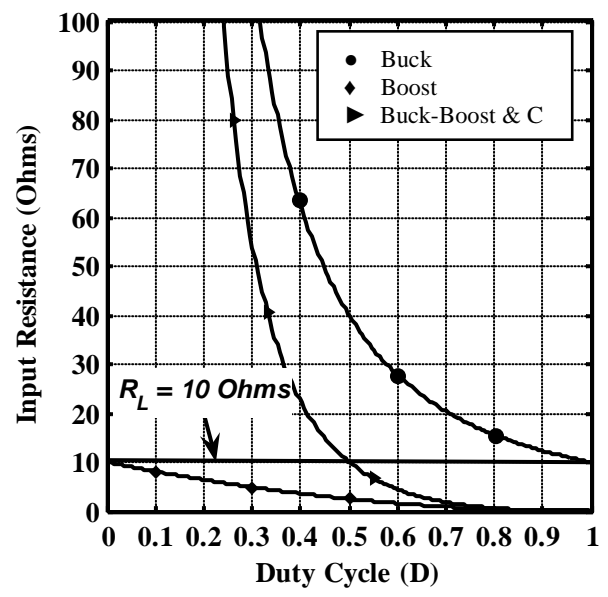

Fig. 6 Effect of D on the input impedance for different topologies of DC-DC converter for RL $=10$ $\Omega$

3.2 Effect of Duty Cycle on Ri for Different Topologies of DC-DC Converter.

The input impedance of DC-DC converter connected to a load $R_{L}$, is the most important performance parameter for the converter. Because the operation of the converter as a MPPT depends basically on this parameter as discussed before. Fig. 6 shows the effect of $D$ on $R_{i}$ for different converter topologies connected to a fixed resistive load $R_{L}=10 \Omega$. For 
buck converter $R_{i}$ is always larger than $R_{L}$. Thus $R_{\text {opt }}$ must be greater than $R_{L}$, in order to be matched using the converter as $R_{L A}$ in Fig. 2. On the other hand, for boost converter, $R_{i}$ is always less than $R_{L}$. Thus $R_{\text {opt }}$ should be less than $R_{L}$ as $R_{L C}$ in Fig. 2. For buckboost and c'uk converter, when $(0 \leq D<0.5), R_{i}>R_{L}$ , to operate as a buck converter, and for $(0.5<D \leq$ 1 ), $R_{i}<R_{L}$, to operate as a boost converter. Thus this topology has no restricted zone and the load may have any value.

\section{EFFECT OF CHANGING ATMOSPHERIC CONDITIONS ON THE CONVERTER OPERATION AND DESIGN}

When the solar radiation and/or the cell temperature changes during the day, the MPP of the PV module will change, and thus Ropt, which the MPPT has to track. Then the MPPT must adjust $\mathrm{D}$, in order to track the new Ropt. The converter boundaries (Cmin and Lb) will therefore change. So these parameters will be affected by the change in climatic conditions, which will effect on the converter performance. This effect will be studied in this section for different topologies of DC-DC converter when operate as a MPPT for a PV module with resistive load.
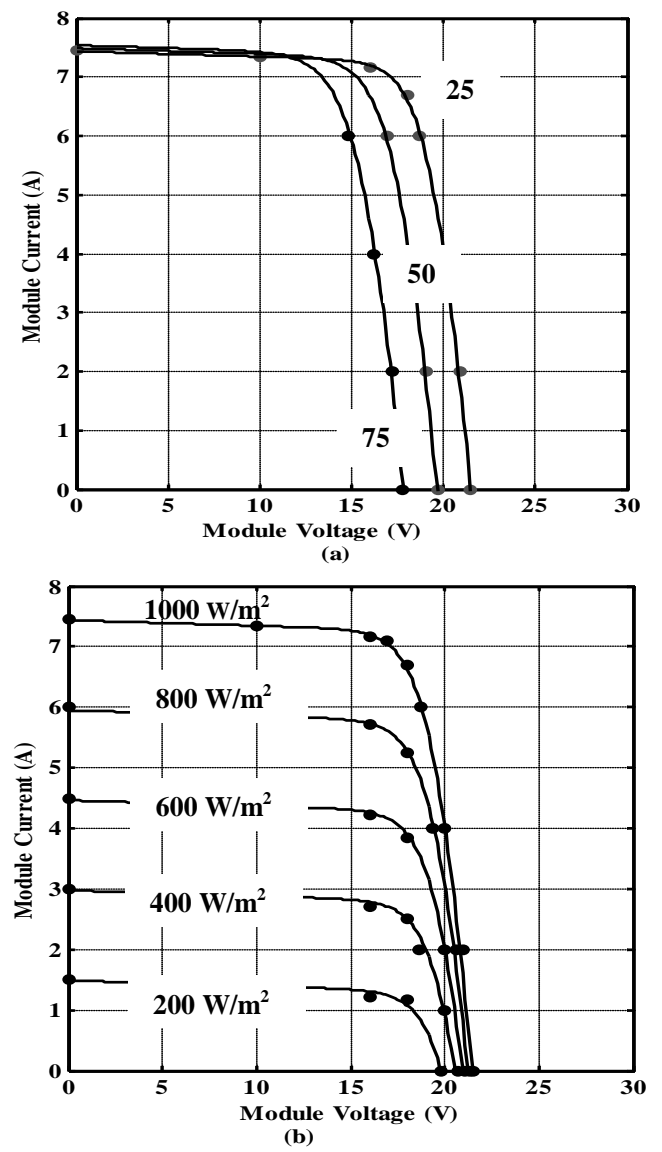

Fig. 7 I-V curves of KC-120-1 PV module (a) At different temperatures and $1 \mathrm{~kW} / \mathrm{m} 2$ (b) At different irradiance intensity and 25oC: simulation results using MATLAB model [8]

\subsection{The Experimental Module}

The following simulation work is carried out under the atmospheric conditions in EGYPT. Kyocera KC120-1 commercial PV module, is chosen as a PV generator in MATLAB simulation model. The module consists of 36 multi-crystalline silicon solar cells in series and provides $120 \mathrm{~W}$ of nominal maximum power [27]. The MATLAB model gives a good correspondence between the data points and the simulated I-V curves as shown in Fig. 7. The discrete points are taken from the datasheet while the continuous lines are obtained by simulation. The series and parallel resistances are calculated by the MATLAB model for the chosen module, such that $\mathrm{Rs}=4.7 \mathrm{~m} \Omega$ and $\mathrm{Rp}=2.9953$. The MATLAB model searches for the value of $n$ which achieves the best agreement between the datasheet points and the $\mathrm{I}-\mathrm{V}$ curve of the module. This value of $\mathrm{n}$ is found to be 1.05. Fig. 8 shows the meteorological data used for this study. These data have been measured for the model located on the roof of a building in EGYPT, on the $10^{\text {th }}$ day of Augusts 2010. The figure shows that the worst radiation during that day was 100 $\mathrm{W} / \mathrm{m}^{2}$ at $15^{\circ} \mathrm{C}$ while the best radiation was 1000 $\mathrm{W} / \mathrm{m}^{2}$ at $50^{\circ} \mathrm{C}$. Using the MATLAB simulation model, values of $R_{\text {opt(min) }}$ and $R_{\text {opt(max) }}$ corresponding to the best and the worst atmospheric conditions are calculated and are shown in Fig. 9. Where $R_{\text {opt }}$ for the module can be calculated at a certain conditions by:

$$
R_{\text {opt }}=V_{\text {mpp }} / I_{\text {mpp }}
$$

Thus from Eq. (2) and Fig. 9, the data in table 2 can be deduced

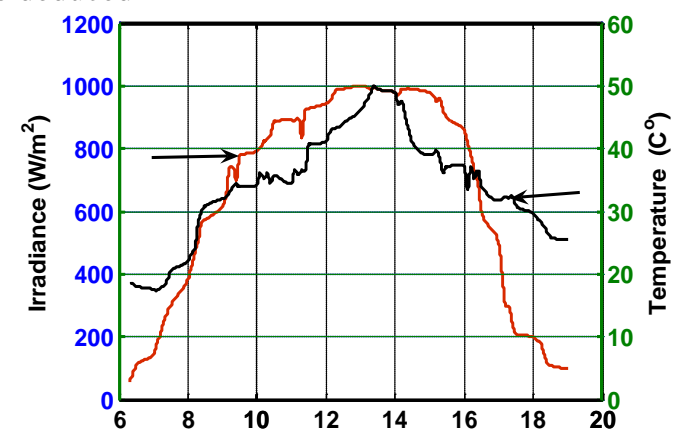

Fig. 8 Cell temperature and solar radiation values for

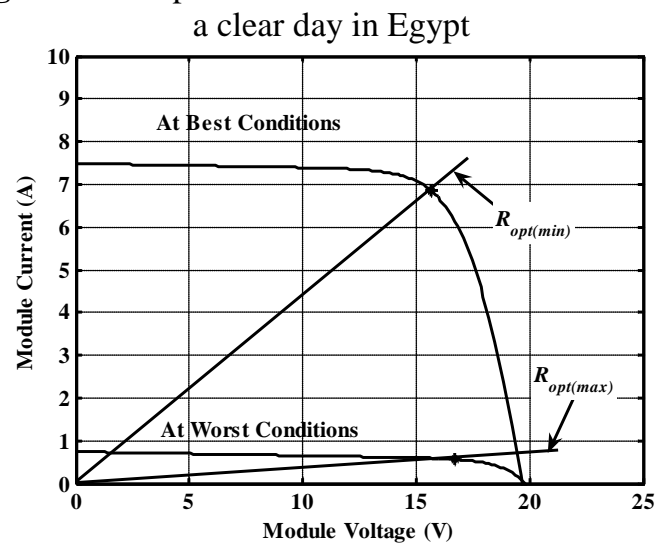

Fig. 9 The optimum impedance at the best and the worst atmospheric conditions 
M. A. Farahat, H. M. B. Metwally, and A. A. A. Mehrem, "Optimal Choice and Design of Different ..."

Table 2, MPPs data at the best and the worst atmospheric conditions

\begin{tabular}{|c|c|c|c|c|}
\hline Conditions & $P_{m}(W)$ & $\begin{array}{l}I_{m p p} \\
(A)\end{array}$ & $\begin{array}{l}V_{m p p} \\
(V)\end{array}$ & $R_{o p t}(\Omega)$ \\
\hline $\begin{array}{l}\text { Best } \\
\text { conditions }\end{array}$ & 109.2811 & 6.855 & 15.65 & $\begin{array}{l}R_{\text {opt(min) }} \\
2.28\end{array}$ \\
\hline $\begin{array}{l}\text { Worst climatic } \\
\text { conditions }\end{array}$ & 9.4237 & 0.564 & 16.71 & $\begin{array}{c}R_{o p t(\max )}= \\
29.63\end{array}$ \\
\hline $\begin{array}{l}\text { STC }\left(1000 \mathrm{~W} / \mathrm{m}^{2},\right. \\
\left.25^{\circ} \mathrm{C} \text { and } 1.5 \text { A.M }\right)\end{array}$ & 120 & 7.1 & 16.9 & $\begin{array}{c}R_{\text {opt }(S T C)} \\
2.38\end{array}$ \\
\hline
\end{tabular}

\subsection{Operation Analysis}

In the following subsections, the capability of different MPPT topologies to match the optimum impedance under different climatic conditions will be investigated. Resistive load is assumed in each case.

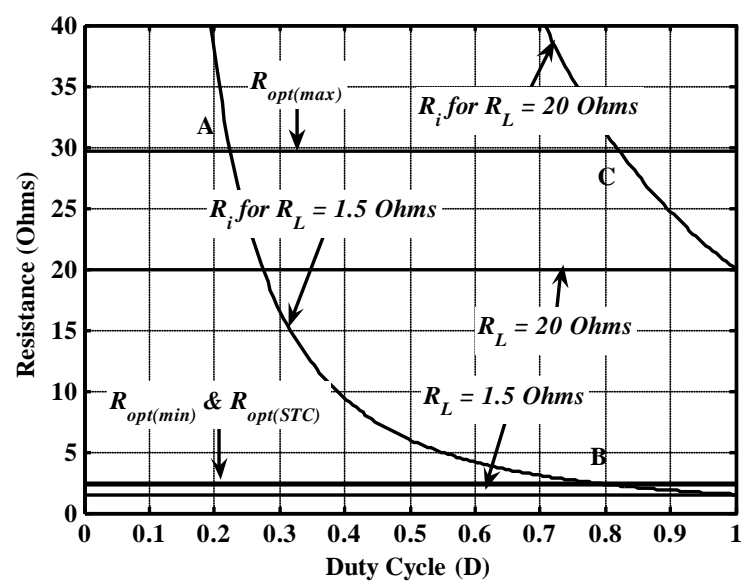

Fig. 10 Operation of MPPT based on buck converter

\subsubsection{Buck Converter Operation Analysis}

The effect of changing the optimum impedance due to change in atmospheric conditions, on MPPT operation based on buck converter with different resistive loads is shown in Fig. 10. The figure shows that, when $R_{L}=1.5 \Omega<R_{\text {opt(min), }}$, the converter is capable of matching the MPP under different atmospheric conditions. But when $R_{\text {opt(min) }}<R_{L}=20 \Omega$ $<R_{\text {opt(max) }}$, the matching can be achieved as long as $R_{\text {opt }} \geq R_{L}=20 \Omega$, otherwise the converter fails to track the MPP. For $R_{L}>R_{\text {opt(max) }}$, the converter can't track the MPP at all. So to get the optimum MPPT operation based on buck converter under different climatic conditions along the period, the load impedance should be close to but less than $R_{\text {opt(min) }}$ for the PV module. The conditions can be made more practical through the assumption that, $R_{\text {opt(min) }}$ of PV module is approximately equal to the optimum impedance at STC $\left(R_{\text {opt }(S T C)}\right)$, which can easily be calculated from the provided manufacture's data.

\subsubsection{Boost Converter Operation Analysis}

Fig. 11 shows the effect of changing the optimum impedance due to change in climatic conditions, on the MPPT operation based on boost converter with different resistive loads. The figure shows that, when
$R_{L}=35 \Omega>R_{\text {opt(max) }}$, the converter is capable of tracking the MPP at all. But when $R_{L}=20 \Omega, R_{\text {opt(min) }}$ $<R_{L}<R_{\text {opt(max) }}$, the matching is available as long as $R_{\text {opt }} \geq R_{L}$. If $R_{L}<R_{\text {opt(min) }}$, the converter can't track the MPP at all. Briefly speaking, in order to ensure the best performance of the MPPT based on boost converter under different climatic conditions, the load impedance must be close to but larger than $R_{\text {opt(max) }}$ for the PV module.

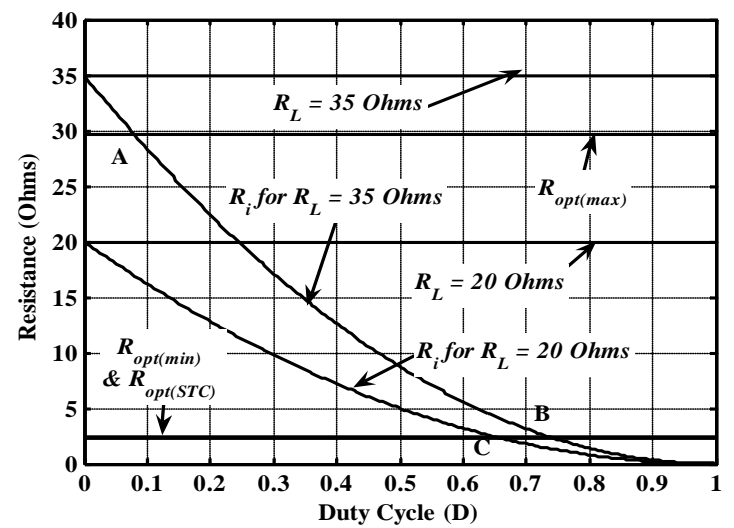

Fig. 11 Operation of MPPT based on boost converter

\subsubsection{C'uk and Buck-Boost Converter Operation Analysis}

The operation of c'uk and buck-boost converters is the same, as displayed in Fig. 12. Three different resistive loads are chosen in this study to cover all possible cases. For $R_{L}=35 \Omega>R_{\text {opt(max) }}$, the matching occurs at points $\mathrm{C}$ and $\mathrm{D}$. In this case the converter operates as a boost converter at all. The second load is $R_{L}=1.5 \Omega, R_{L}<R_{\text {opt(mim) }}$, the matching occurs at points $\mathrm{E}$ and $\mathrm{F}$, and the converter operates as a buck converter. The last load is $R_{L}=20 \Omega, R_{\text {opt(min) }}<R_{L}<$ $R_{\text {opt(mim) }}$. At best conditions the matching occurs at point $\mathrm{B}$, and the converter operates as a boost converter. At worst conditions the matching occurs at point $\mathrm{A}$, and the converter operates as a buck converter. Thus the converter is capable of tracking the MPP under different conditions along the period. Thus, the imposed restrictions for the two previous converter topologies do not affect the c'uk converter. Therefore there is no mismatching zone in this topology. In this section we demonstrate that only the c'uk converter is able to follow the photovoltaic panel maximum power point at all times, regardless of cell temperature, solar global irradiation and connected load.

\subsection{Design Analysis}

When the atmospheric conditions change during the day, the MPP will change. Thus the MPPT must adjust $D$, in order to track the new MPP. Thus $C_{\text {min }}$ and $L_{b}$ will also change, and may become greater than the chosen converter design parameters. Therefore, the converter may work in the DCM with large ripple in the output voltage which reduce the converter efficiency and lead to non-optimal 
utilization of semiconductor switches and passive components [1]. In order to avoid this problem, the behavior of these boundaries under the influence of changing climatic conditions must be studied carefully. In order to reach the best choice for the design parameters and achieve the optimal converter performance regardless of cell temperature and solar radiation. Using the relationships given in table 1 and assuming:

1. A typical frequency of $100 \mathrm{kHz}$.

2. Suitable load resistance for each converter.

3. A percentage ripple of $1 \%$ in the output voltage.

The effect of change of $D$, as a result of changed atmospheric conditions, on the design of different topologies of DC-DC converter, will be studied.

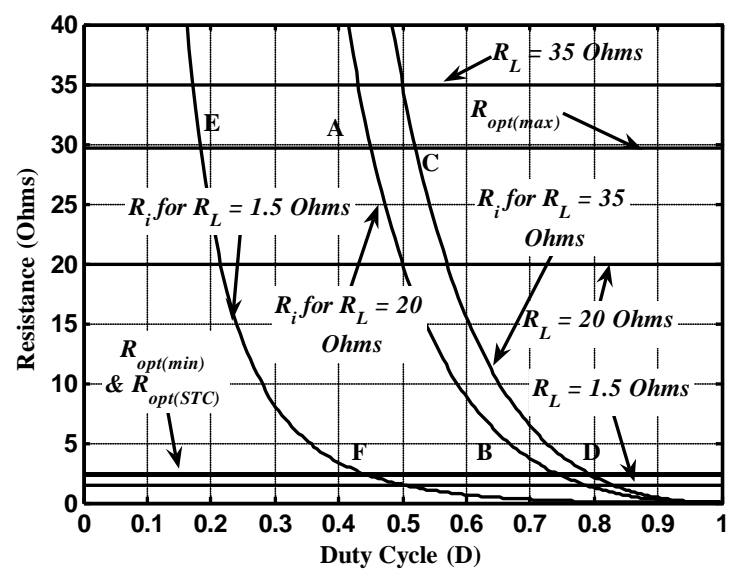

Fig. 12 Operation of MPPT based on c'uk or buckboost converter.

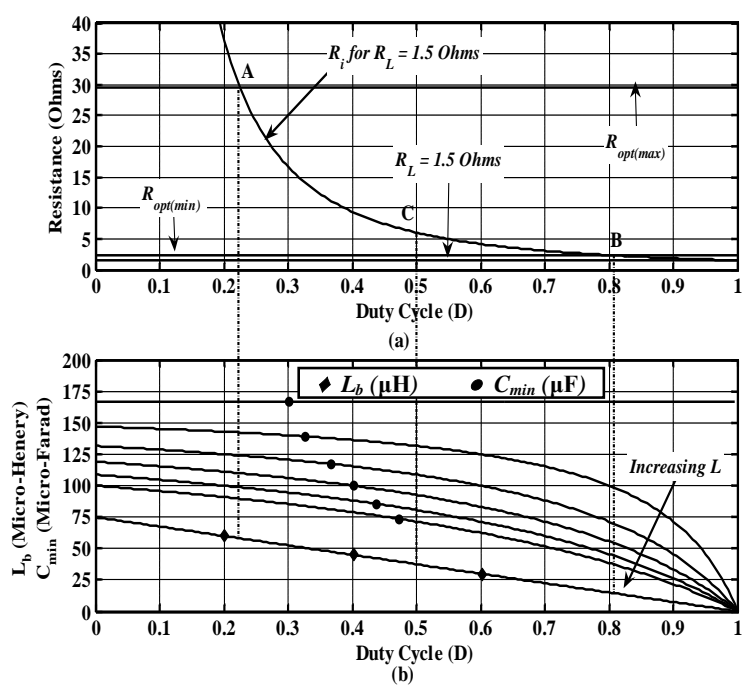

Fig. 13 Effect of duty cycle on buck converter design, (Note: $\mathrm{L}_{\mathrm{b}}$ is multiplied by 10 )

\subsubsection{Buck Converter Analysis}

A suitable load for buck converter is chosen to be 1.5 $\Omega$, as shown in Fig. 13-a. Fig. 13-b shows the effect of change in $D$ on $L_{b}$ and $C_{\min }$, where $C_{\min }$ is drawn with different values of filter inductance $(L)$, the inductance starts at $L_{b}$ and increases in steps of $1 \mu \mathrm{H}$. When $L=L_{b}, C_{\min }$ is independent of $D$, But increasing $L$ over $L_{b}$, gives a significant reduction in $C_{\text {min }}$. Thus it's preferable to choose the filter inductance slightly greater than $L_{b}$. The input impedance matches $R_{\text {opt(max) }}$ and $R_{\text {opt(min) }}$ at points A and $\mathrm{B}$ in Fig. 13-a. And the duty cycle changes from 0.22 to 0.81 , and in turns $L_{b}$ decreases from $5.84 \mu \mathrm{H}$ $\left(L_{b_{-} \max }\right)$ to $1.43 \mu \mathrm{H}\left(L_{b_{-} \min }\right)$. If the operating point was at point $C$, the duty cycle is 0.5 , and $L_{b}=3.7 \mu \mathrm{H}$, if the filter inductance $(L)$ is chosen to be equal to $L_{b}(L$ $=L_{b}$ ), then if $D$ is decreased to 0.4 (as a result of changing atmospheric conditions), the boundary inductance will increase to $4.5 \mu \mathrm{H}$ to be larger than $L$. At this condition the converter will operate in DCM. Thus $L$ must be larger than $L_{b \_\max }$, which always occurs at the worst atmospheric conditions for all loads smaller than $R_{\text {opt(max), to give a }}$ continuous operation in CCM regardless of the atmospheric conditions. For the filter capacitance design (C), if $L$ is chosen to give the lower line for $C_{\min }$ in Fig. 13-b, when the operating point moves from A to B, $C_{\min }$ will decrease from $89.5 \mu \mathrm{F}$ to 37.1 $\mu \mathrm{F}$. If point $\mathrm{C}$ was the operating point, $C_{\min }=71.22$ $\mu \mathrm{F}$. If the filter capacitance is chosen to equal $C_{\min }$, then if $D$ is decreased to $0.4, C_{\min }$ will increase to $78.8 \mu \mathrm{F}$ to be larger than $C$. At this conditions the ripple in output voltage will be larger than the required limit. Thus in order to avoid this difficulty, the filter capacitance must be larger than the maximum value for $C_{\min }\left(C_{\min (\max )}\right)$, which always occurs at the worst atmospheric conditions for all loads smaller than $R_{\text {opt(max) }}$.

\subsubsection{Boost Converter Analysis}

A suitable load is chosen for this study to be $35 \Omega$ as shown in Fig. 14-a. The effect of changing $D$ on $C_{\text {min }}$ and $L_{b}$ is shown in Fig. 14-b, which indicates that, as $D$ is increased, $C_{\min }$ will increase linearly, but $L_{b}$ will change in a hill curve, the top of the hill is $L_{b \text {-peak }}$. When the atmospheric conditions change from the worst to the best value, the operating point moves from A to B respectively. During this period $D$ changes from 0.08 to 0.74 . In turns $C_{\min }$ and $L_{b}$ will change such that, $C_{\min }$ increases linearly from 2.297 $\mu \mathrm{F}$ to $21.25 \mu \mathrm{F}$, and $L_{b}$ changes from 11.9 to 8.55 $\mu \mathrm{H}$. The filter capacitance must be greater than $C_{\min (\max )}$, which always at the best conditions for all loads greater than $R_{\text {opt(min). For filter inductance }}$ design, it should be larger than $L_{b_{-} \max }$, which may be any location during the period. The location of $L_{b \_ \text {max }}$ depends on the operating period, which depends on the load value, atmospheric conditions and characteristics of PV module. For our conditions $L_{b_{-} \text {max }}=L_{\text {b-peak }}=25.93 \mu \mathrm{H}$ and occurs at $D=0.333$. Briefly speaking, If the crest of $L_{b}$ curve, lies in the operating period, then $L_{b_{-} \text {max }}=L_{\text {b-peak }}$, and can be calculated at $R_{L}=35 \Omega$ and $f=100 \mathrm{kHz}$, by:

$$
L_{b}=1.75 \times 10^{-4}(1-D)^{2} D
$$

To calculate the duty cycle at the crest of the curve $\left(D_{m}\right)$, 


$$
d L_{b} / d D=0
$$

By solving Eq. (4), two values of $D_{m}$ are obtained 1, $1 / 3$. Thus $L_{b \text {-peak }}$ occurs at $D_{m}=1 / 3$, and it's value can be calculated from Eq. (3), $L_{b-p e a k}=25.9 \mu \mathrm{H}$, which is the same value taken from the curve. Note that the value of $D_{m}$ is constant and independent on any other parameters, thus the crest of the curve always occurs at $D_{m}=0.333$. But if $D=0.333$ is not in the operating range, then the previous analysis must be used to calculate $L_{b_{-} \max }$. As an example for this case, if the operating period is between points $\mathrm{C}$ and B in Fig. 14.

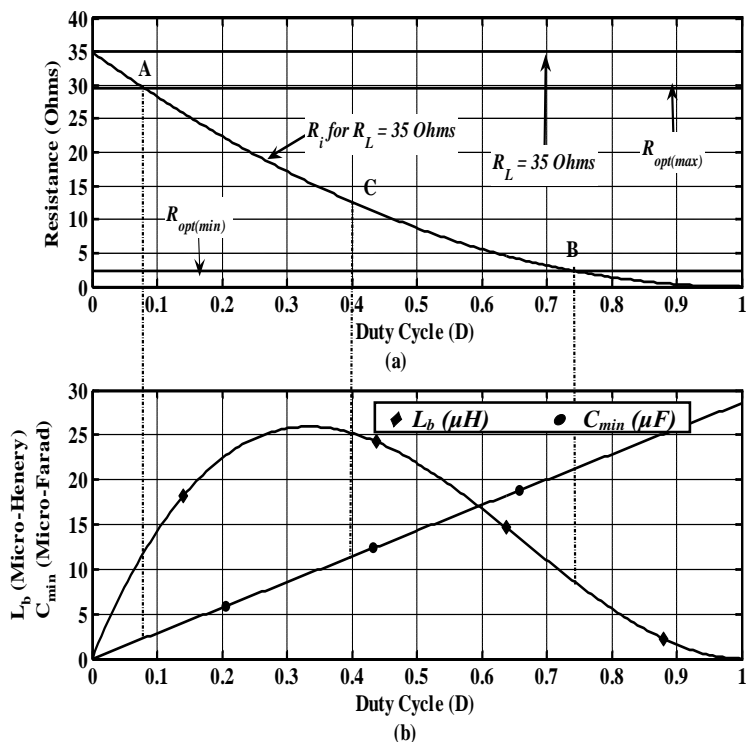

Fig. 14 Effect of duty cycle on boost converter design
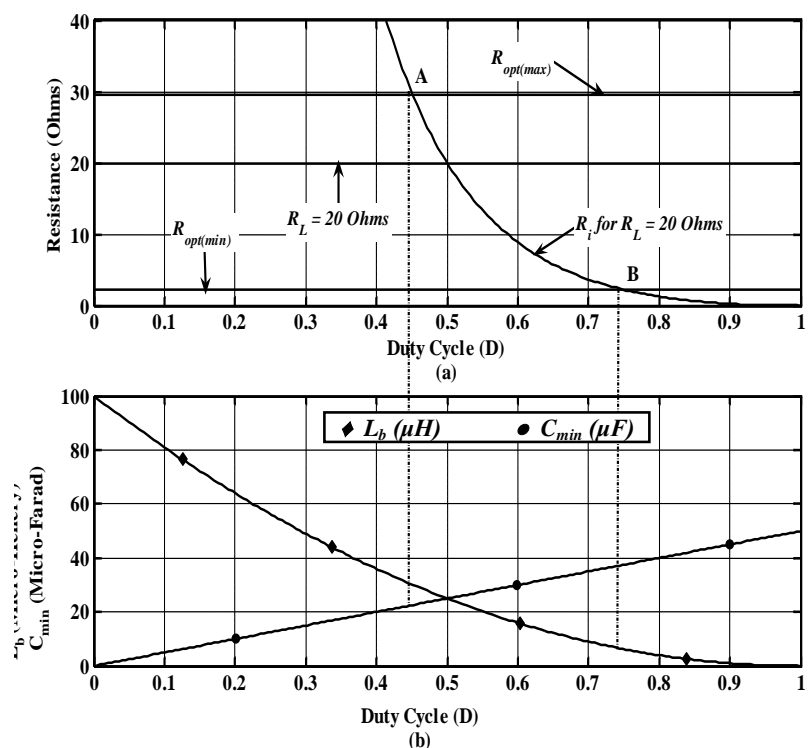

Fig. 15 Effect of duty cycle on buck-boost converter design

\subsubsection{Buck-Boost Converter}

As the buck-boost converter haven't any restriction for the load value. Thus $R_{\text {opt(min) }}<R_{L}=20 \Omega<R_{\text {opt(max) }}$, is used in this study as shown in Fig. 15-a. When the atmospheric conditions were changed from the worst to the best conditions, the operating point moves from A to B as shown in Fig. 15-a. And $D$ changes from 0.45 to 0.744 . Also $L_{b}$ and $C_{\min }$ will change. $C_{\text {min }}$ increases linearly from $22.36 \mu \mathrm{F}$ to $37.9 \mu \mathrm{F}$. Unlike $L_{b}$, which has the same behavior as the boost converter. For continuous operation in CCM, $L$ must be larger than $L_{b \max }$, which is always at worst conditions for all loads. And to limit the ripple in output voltage at a certain value, $C_{\min }$ must be larger than $C_{\min (\max )}$, which is always at the best conditions for all loads.

\subsubsection{C'uk Converter}

The load conditions of c'uk converter are exactly the same as that of buck-boost converter, as shown in Fig. 16-a. This type of converter contains four design parameters, and this is the main disadvantage of it. These parameters are $L_{1}, C_{1}, L_{2}$ and $C$. For permanent operation in CCM, $L_{1}$ and $L_{2}$ must be greater than $L_{1 b}$ and $L_{2 b}$ respectively. And for a limited ripple value in output voltage, $C$ must be greater than $C_{\min }$. Also to limit the ripple in the voltage across capacitor $C_{1}$, the capacitance $C_{1}$ must be lager than $C_{1-\text { min }}$. Fig. 16-b shows the effect of $D$ on all these parameters. Where $C_{\min }, L_{1 b}$ and $L_{2 b}$ decrease as $D$ is increased. Unlike $C_{1-\min }$, which increases as $D$ is increased. For c'uk converter, $C_{\text {min }}$ and $L_{2 b}$ are similar to that for buck converter. Therefore they have the same behavior, as indicated in Fig. 16-b, where $L_{2}$ is increased from $L_{2 b}$ in step of $1 \mu \mathrm{H}$. In order to get the best performance from the converter under various atmospheric conditions, The parameters $\left(L_{1}, L_{2}\right.$ and $\left.C\right)$ must be greater than their values at the worst atmospheric conditions. But $C_{1}$ must be greater than its value at the best atmospheric conditions.

Figure 17 shows another example for this study, at which all conditions are kept constant for all types of converters, except the duty cycle which changes as a result of changed climatic conditions. The same load is chosen here for all types, such that $R_{\text {opt(min) }}<R_{L}=$ $20 \Omega<R_{\text {opt(max). }}$. This example is useful for making a comparison between the boundaries of design parameters for different topologies. Also it's an example for using a non optimal chosen load with buck and boost converter. As the climatic conditions changed, The operating region for each type is indicated in Fig. 17 by the double arrow line. The results from the previous discussion for different types of converters are summarized in table 3 , which contains the location of $L_{b_{-} \max }$ and $C_{\min (\max )}$, that we are looking for. These results are general for all types of modules and loads under the given conditions.

The results of the comparison between $L_{b}$ and $C_{\text {min }}$ for all types of DC-DC converters at the same conditions, are displayed in table 4 . The results were 
taken from Fig. 17 at $D=0.4$ and 0.6. The table indicates that the c'uk converter has the largest values of boundary inductance, and is followed by the buck converter, and then the buck-boost and finally boost converter has the smallest values. On the other hand, the buck-boost and the boost converter have the largest $C_{\min }$, and then the buck and c'uk.

Table 3, Location of $\mathrm{L}_{\mathrm{b} \_\max }$ and $\mathrm{C}_{\min (\max )}$, for different topologies of converters

\begin{tabular}{lcc}
\hline Converter & $L_{b \max }$ & $C_{\min (\max )}$ \\
\hline $\begin{array}{l}\text { Buck (for all loads smaller } \\
\text { than } R_{\text {opt(max) }} \text { ) }\end{array}$ & Worst & Worst \\
$\begin{array}{l}\text { Boost (for all loads larger } \\
\text { than } R_{\text {opt(min) }} \text { ) }\end{array}$ & Unknown & Best \\
$\begin{array}{l}\text { Buck-Boost (for all values } \\
\text { of loads) }\end{array}$ & Worst & Best \\
$\begin{array}{l}\text { C'uk (for all values of } \\
\text { loads) }\end{array}$ & $\begin{array}{c}\text { Worst } \\
\text { conditions }\end{array}$ & Worst \\
\hline
\end{tabular}

Table 4, Comparison between the boundaries for all types of converters at $\mathrm{R}_{\mathrm{L}}=20 \Omega$

\begin{tabular}{ccccc}
\hline & Buck & Boost & Buck-Boost & C'uk \\
\hline & $L_{b}=59.8$ & $L_{b}=14.38$ & $L_{b}=35.76$ & $L_{1 b}=148.7$ \\
$D=$ & $\mu \mathrm{H}$ & $\mu \mathrm{H}$ & $\mu \mathrm{H}$ & $\mu \mathrm{H}$ \\
0.4 & & & & $L_{2 b}=59.8$ \\
& $C_{\text {min }}=12.29$ & $C_{\text {min }}=20.1$ & $C_{\text {min }}=20.1$ & $\mu \mathrm{H}$ \\
& $\mu \mathrm{F}$ & $\mu \mathrm{F}$ & $\mu \mathrm{F}$ & $C_{\text {min }}=$ \\
& & & $12.29 \mu \mathrm{F}$ \\
\hline & $L_{b}=39.7$ & $L_{b}=9.503$ & $L_{b}=15.76$ & $L_{1 b}=65.83$ \\
$0=$ & $\mu \mathrm{H}$ & $\mu \mathrm{H}$ & $\mu \mathrm{H}$ & $\mu \mathrm{H}$ \\
0.6 & & & & $L_{2 b}=39.7$ \\
& $C_{\text {min }}=12.19$ & $C_{\text {min }}=$ & $C_{\min }=$ & $\mu \mathrm{H}$ \\
& $\mu \mathrm{F}$ & $30.15 \mu \mathrm{F}$ & $30.15 \mu \mathrm{F}$ & $C_{\min }=$ \\
& & & & $12.19 \mu \mathrm{F}$ \\
\hline
\end{tabular}

\section{ConClusions}

This paper studies the effect of changing cell temperature and solar radiation in Egypt, on the choice of a suitable DC-DC converter to operate as a MPPT in PV systems. In this work we concluded that, for achieving the optimal operation for different converter topologies, regardless of changing atmospheric conditions, the buck converter should be used with a load impedance close to but less than $R_{\text {opt }}$ at the best conditions. But the boost converter must be used with a load impedance close to but larger than $R_{\text {opt }}$ at worst conditions. Only the buck-boost and the c'uk converter are capable of achieving the optimal operation regardless of the load value. On the other hand the c'uk converter has the highest values of reactive components, which is the main drawback for this type. In addition, this paper investigates the effect of changing climatic conditions on the design of each type of converter. How to achieve the optimal design regardless of these conditions is also studied. For a permanent operation in CCM the filter inductance for all topologies must be greater than the maximum value of $L_{b}$, which occurs at the worst climatic conditions for all topologies except the boost converter which may occurs at any location during the period. Also in order to limit the ripple in the output voltage below a certain value, the filter capacitance must be larger than the maximum value of $C_{\min }$. This value of $C_{\min }$ occurs at worst conditions for buck and c'uk converter, and occurs at best conditions for boost and buck-boost converter.

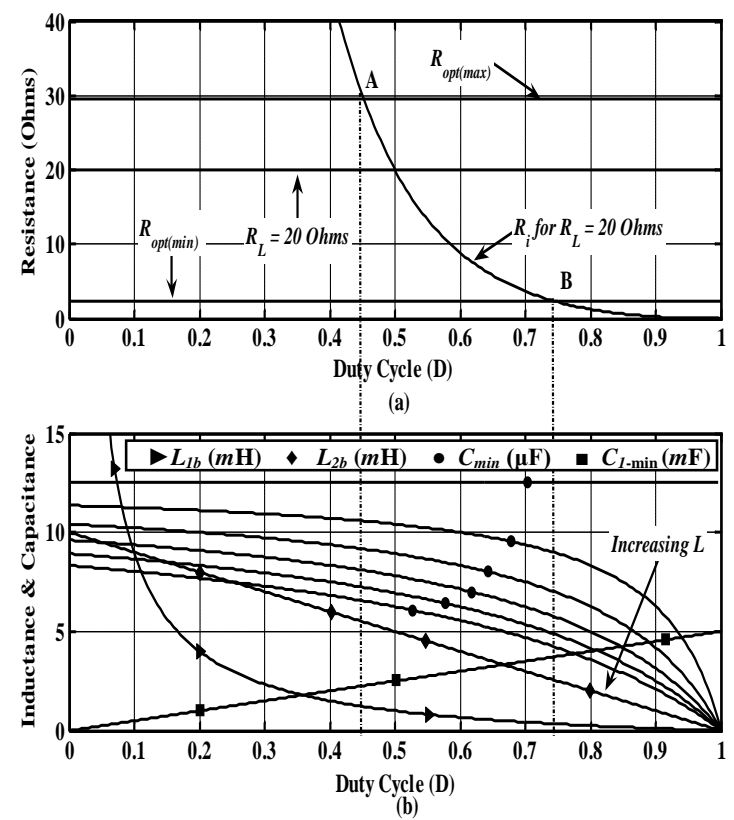

Fig. 16 Effect duty cycle on c'uk converter design. (note: L1b is multiplied by 10, and L2b \& C1-min are multiplied by 100) 


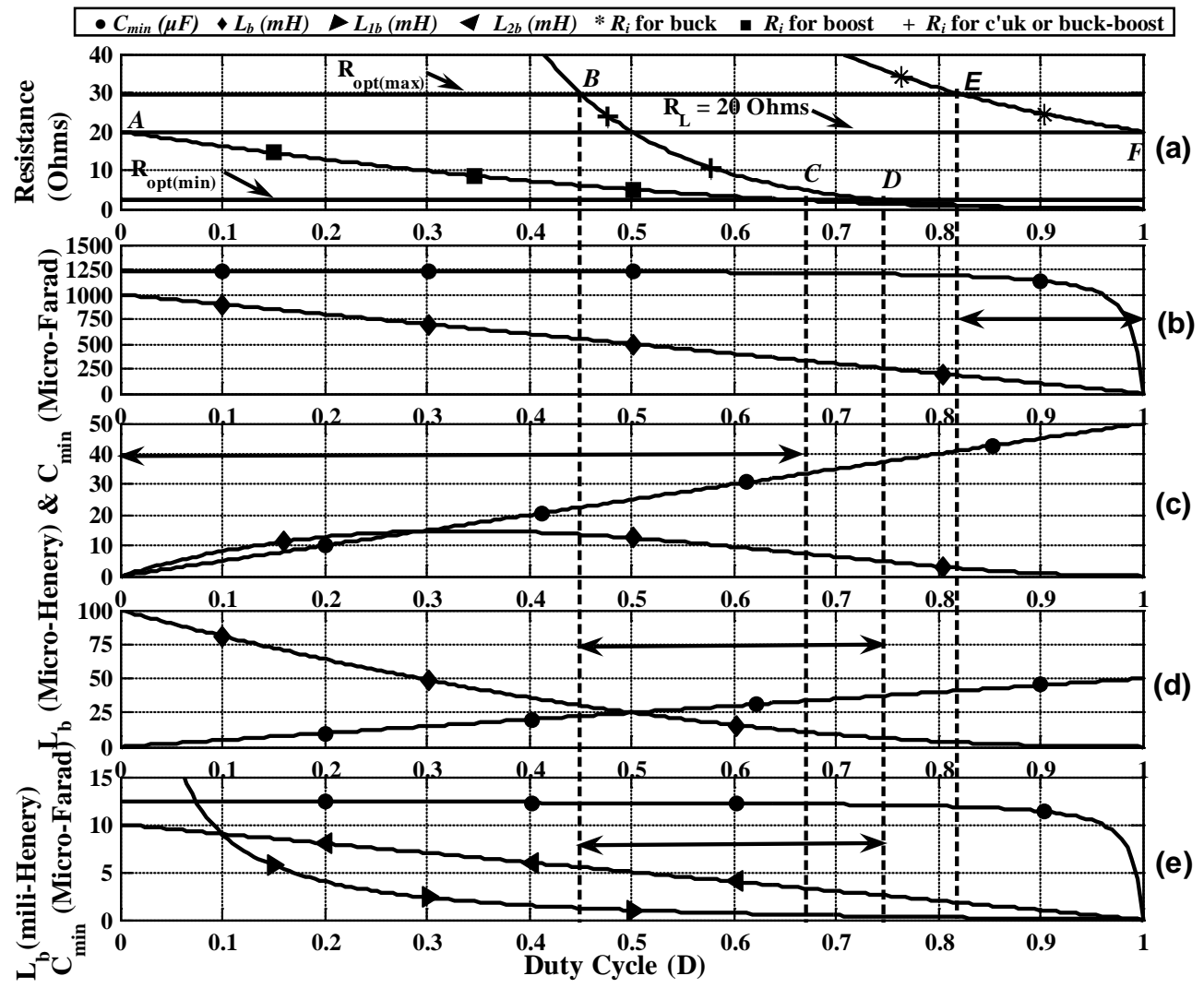

Fig. 17 Effect of duty cycle on DC-DC converter design. (a) For all converters (b) Buck (c) Boost (d) BuckBoost (e) C'uk. (note: Lb for buck \& L1b are multiplied by 10, and L2b \& Cmin for buck are multiplied by 100)

\section{REFERENCES}

[1] M. Rashid "Power Electronics -Circuits, Devices and Application s ", $3^{\text {rd }}$ Edition Pearson Education, (2004).

[2] Oi. Akihiro "Design and Simulation of Photovoltaic Water Pumping System", M.Sc. Thesis, Univ. of California Polytechnic, (2005).

[3] T. Takashima, T. Tanaka, M. Amano and Y. Ando "Maximum output control of photovoltaic (PV) array", Intersociety Energy Conversion Engineering Conference and Exhibit (IECEC), 35th, Las Vegas, NV, July 24-28, 2000, pp. 380-383.

[4] N. Takehara and S. Kurokami "Power control apparatus and method and power generating system using them". Patent US5,654,883. 1997

[5] H.E.-S.A. Ibrahim, et al. "Microcomputer controlled buck regulator for maximum power point tracker for DC pumping system operates from photovoltaic system, Fuzzy Systems" Conference Proceedings, FUZZIEEE '99, 1999 IEEE International 1 (22-25) (1999) 406-411.

[6] M.A.S. Masoum, et al. "Optimal power point tracking of photovoltaic system under all operating conditions", in: 17th Congress of the World Energy Council, Houston, TX, 1998.

[7] J.J. Schoeman and J.D. van Wyk "A simplified maximal power controller for terrestrial photovoltaic panel arrays", IEEE Power Electronics Specialists Conference. PESC '82 Record. New York, NY, 1982, pp. 361-367.

[8] S.M. Alghuwainem "Matching of a dc motor to a photovoltaic generator using a step-up converter with a current-locked loop", IEEE Trans. Energy Conversion 9 (1994) 192-198.

[9] T. Noguchi, et al. "Short-current pulse-based adaptive maximum power point tracking for a photovoltaic power generation system", Elect. Eng. Japan 139 (1) (2002) 65-72.

[10] J.H. David "Power conditioning system", US3,384,806, 1968.

[11] L.T.W. Bavaro "Power regulation utilizing only battery current monitoring", Patent, US4,794,272, 1988.

[12] Y. Kim, H. Jo and D. Kim "A new peak power tracker for cost-effective photovoltaic power systems", IEEE Proc. Energy Conversion Eng. Conf. IECEC 963 (1) (1996) 1673-1678.

[13] H. Al-Atrash, I. Batarseh and K. Rustom "Statistical modeling of DSP-based hill-climbing MPPT algorithms in noisy environments Applied Power Electronics" Conference and Exposition, 2005. APEC 2005, Twentieth Annual IEEE, vol. 3, 6-10 March 2005, pp. 1773-1777.

[14] K.H. Hussein, I. Muta, T. Hoshino and M. Osakada "Maximum photovoltaic power 
tracking: an algorithm for rapidly changing atmospheric conditions", IEE Proc. Generation Transmission Distrib. 142 (1) (1995) 59-64.

[15]D.P. Hohm and M.E. Ropp "Comparative study of maximum power point tracking algorithms", Prog. Photovolt: Res. Appl. 11 (2003) 47-62.

[16]X. Liu and L.A.C. Lopes, "An improved perturbation and observation maximum power point tracking algorithm for PV arrays", in: Power Electronics Specialists Conference, 2004, PESC 04. 2004, IEEE 35th Annual vol. 3, 2004, 2005-2010.

[17] V. Salas, E. Ol1'as, A. La' zaro and A. Barrado "New algorithm using only one variable measurement applied to a maximum power point tracker", Solar Energy Mater. Solar Cells 1-4 (2005) 675-684.

[18] V. Salas, E. Olı'as, A. La' zaro and A. Barrado "Evaluation of a new maximum power point tracker (MPPT) applied to the photovoltaic stand-alone systems", Solar Energy Mater. Solar Cells 87 (1-4) (2005) 807-815.

[19] K.K. Tse, H.S.H. Chung, S.Y.R. Hui and M.T. Ho "A novel maximum power point tracking technique for PV panels", in: IEEE Power Electronics Specialists Conference, 2001, PESC. 2001 IEEE, vol. 4, 1970-1975.

[20]A. Cocconi and W. Rippel "Lectures from GM sunracer case history, lecture 3-1: the Sunracer power systems". Number M-101, Society of Automotive Engineers, Inc., Warderendale, PA, 1990.

[21]B.M. Wilamowski, et al. "Microprocessor implementation of fuzzy system and neural networks", in: International Joint Conference on Neural Networks, vol. 1, Washington, DC, 2001, pp. 234-239.

[22]M. Miyatake, T. Kouno and M. Nakano "A simple maximum power point tracking control employing Fibonacci search algorithm for power conditioners of photovoltaic generators", EPEPEMC'02, Cavtat \& Dubrovnik, 2002.

[23] A.N. Abd El-Shafy, H.F. Faten and E.M. Abou El-Zahab "Evaluation of a proper controller performance for maximum-power point tracking of a stand-alone PV system", Solar Energy Mater. Solar Cells 75 (3-4) (2003) 723-728.

[24] N. Patcharaprakiti，S. Premrudeepreechacharn and Y. Sriuthaisiriwong "Maximum power point tracking using adaptive fuzzy logic control for grid-connected photovoltaic system", Renew. Energy 30 (11) (2005) 1771-1788.

[25]A. Betka "Perspectives for the Sake of Photovoltaic Pumping Development in the South", M.Sc. Thesis, Unvi. of Batna, (2002).
[26] J. Enrique, E. Durán, M. Sidrach-de-Cardona and J. Andu' jar "Theoretical Assessment of the Maximum Power Point Tracking Efficiency of Photovoltaic Facilities with Different Converter Topologies", Solar Energy Mater. Solar Cells 90 (3-4) (2007) 1555-1578.

[27] Kyocera KC120-1 Multi-crystalline Photovoltaic Module Datasheet, (2001).

\section{APPENDIX}

\section{A. List of symbols}

$I_{s} \quad$ Input current to converter, A

$V_{s} \quad$ Input voltage to converter, $\mathrm{V}$

$I_{o} \quad$ Output current from converter, A

$V_{o} \quad$ Output voltage from converter, $\mathrm{V}$

$D \quad$ Converter duty cycle

$L_{b} \quad$ Boundary converter filter inductance, $\mathrm{H}$

$R_{\text {opt }} \quad$ Load impedance at MPP, $\Omega$

$R_{L} \quad$ Load impedance, $\Omega$

$L_{1}, L_{2}, \quad$ C'uk converter parameters

$C_{1}$

$n \quad$ Diode ideality factor

$R_{s} \quad$ Series resistance, $\Omega$

$I_{m p p} \quad$ Output current of solar cell at maximum power point, A

I Output current of solar cell, A

$I_{s c} \quad$ Short-circuit current, A

Io Reverse saturation current, A

$R_{p} \quad$ Parallel resistance, $\Omega$

A.M Air mass

$R_{\text {opt(min) }} \quad R_{\text {opt }}$ at best climatic conditions

MPP Maximum power point

$R_{i} \quad$ Input impedance to converter, $\Omega$

$A_{V} \quad$ Converter voltage gain

$A_{i} \quad$ Converter current gain

$L \quad$ Converter filter inductance, $\mathrm{H}$

C Converter filter capacitance, $\mathrm{F}$

$C_{\min } \quad$ Minimum converter filter capacitance,

$t_{\text {on }} \quad$ Switch on time, sec

MPPT Maximum power point tracker

$V_{r} \quad$ Peak-to-peak output ripple voltage, $\mathrm{V}$

$V \quad$ Output voltage of solar cell, $\mathrm{V}$

$f \quad$ Switching frequency, $\mathrm{Hz}$

$V_{\text {mpp }} \quad$ Output voltage of solar cell at

maximum power point, $\mathrm{V}$

$P_{m} \quad$ Maximum power, $\mathrm{W}$

$T \quad$ Cell temperature, $\mathrm{K}$

$k \quad$ Boltzmann's constant, $1.381 \times 10^{-23} \mathrm{~J} / \mathrm{K}$

$q \quad$ Electron charge, $1.602 \times 10^{-19} \mathrm{C}$

STC Standard test conditions.

$R_{\text {opt(max) }} \quad R_{\text {opt }}$ at worst climatic conditions

$R_{\text {opt(stc) }} \quad R_{\text {opt }}$ at STC. 